\title{
A Collaboration-Based Innovation Model Proposed for the Central Black Sea Universities
}

\author{
Mehmet Emin Aksoy \\ Correspondence: Mehmet Emin Aksoy, Tokat Gaziosmanpaşa University, Educational Faculty, Department of \\ Computer Education and Instructional Technologies, Turkey.
}

\author{
Received: June 3, $2018 \quad$ Accepted: July 18, $2018 \quad$ Online Published: July 19, 2018 \\ doi:10.11114/jets.v6i10.3460 \\ URL: https://doi.org/10.11114/jets.v6i10.3460
}

\begin{abstract}
To compete in today's technology-intensive competitive environment, universities need to be aware of their limitations and collaborate with other universities to overcome them. Several indices that attempt to measure innovation and rank institutions have been proposed. Nevertheless, most innovation indices measure innovation at the political or country level that focuses on a specific country or region. Moreover, national innovation indices investigating innovation level of the universities in Turkey focuses only on their academic activities. This motivated us to design a significantly improved model that attempts to increase collaboration among the universities in Central Black Sea region, providing these under developing universities to observe their innovativeness level in terms of infrastructure as well. Thus, they may identify their infrastructure limitations, specifically for high-tech and high-cost devices, and develop strategic plans that can help them collaborate with other universities to address the limitations. Similar to other indices, the proposed models is neither exhaustive nor definitive, and is open to improvements. The model can be continuously upgraded based on the constructive feedbacks and future researches.
\end{abstract}

Keywords: innovation, model, central black sea, university, collaboration

\section{Introduction}

Innovation is a Latin word and it derives from "innovare", which means novelty (Arpaci, 2010; 2011). Within this context, innovation can be defined as the ideas, processes, services, and technologies that are perceived as new by individuals and society (Rogers, 1962, 2003; Evan, 1993; Beatty \& Gordon, 1991). Schumpeter (1939) described innovation as a new product, service, market, or production process. However, innovation is much more than a new idea, service, or product (Arpaci \& Gürbüz, 2011; 2012). Innovation is something that changes and positively affects society (Arpaci, 2013; 2015). From a corporate viewpoint, innovation should increase business performance of companies and provide a competitive advantage (Soosay \& Hyland, 2005). In short, the importance of innovation lies under its added-value for society and economy (Goswami \& Mathew, 2005).

There is a body of research in literature which focused on why some individuals adopt innovation faster or later than others in the same society and why some innovations are adopted earlier or later than others(Rogers, 2003; Lawson-Body, Willoughby, Illia, \& Lee, 2014; Low, Chen, \& Wu, 2011; Wang, Wang, \& Yang, 2010; Arpaci, 2011). The S Curve, which was proposed by Gabriel Tardein (1903) and also known as innovation diffusion curve, refers the adoption level of an innovation in society based on time. Accordingly, an innovation is adopted by few people in the early time, then the number of people that adopt the innovation increases gradually.

Diffusion of innovation is the transmission process of an innovation within the individuals of a social system in time through communication channels (Rogers, 1962). Adoption of an innovation by people occurs in five steps, which are information, convince, decide, practice/use, and confirm (Rogers, 2003). Individuals are classified into five categories in terms of their adoption levels during the diffusion of innovation. These categories are innovators, early adopters, early majority, late majority, and laggards (Rogers, 2003).

Developed by Rogers (1962), diffusion of innovation model argues that the speed of innovation adoption is affected by some factors such as relative advantage, compatibility, complexity, trialability, and observability. According to this model, these characteristics affect the adoption speed of innovations. Additionally, individuals' perspectives of innovation that vary based on their socio-cultural structures and individual characteristics and their attitudes and willingness to adopt innovation should be taken into account (Rogers, 2003). For example, individuals that are 
characterized as early adopters are willing to use the innovation as soon as it is available while the late majority prefers to use it after an important part of the society uses it.

Innovation is important not only for individuals but for all institutions and organizations including universities as well. According to OECD (2014) report, technology and innovation are the most important driving force of corporate success and economic growth. Countries gain the benefits of economic growth thanks to innovation. Countries that make innovation, create novel technologies, and encourage the acceptance of these technologies grow more rapidly than the others because long-term economic growth depends on the creation and support of environments that support new products and technologies (OECD, 2014). However, shaped through the effects of their socio-cultural environment, institutions and organizations are distinguished from each other in terms of innovativeness due to the differences in their sources and competencies. Depending on these differences, institutions are more or less open to change, adopt novelty earlier or later, and take more or less risks.

Rapid dissemination of information and communication technologies in parallel with the development of information society has increased the transformation rate of world economy into an information-based economy where information is the basic economic input and research and development (R\&D) is the most important innovation source. Universities, where $R \& D$ is among the most important activities, are not only the sources of novel technologies, entrepreneur talents, and national-international collaborations but the driving force of economic development. In today's technology-intensive competitive environment, universities need to be aware of their innovation levels and their rankings among other universities.

The purpose of this study was to design an innovation model that was relatively more advanced than the other national indices and that aimed at improving the collaboration among universities in Central Black Sea Region. The model may help universities in developing regions identify their infrastructure limitations, specifically for high-tech and high-cost devices, and develop strategic plans that can help them collaborate with other universities to address the limitations.

\section{Literature Review}

Various indices were developed to measure innovation and rank institutions at corporate and political level. The indices developed at corporate level measure the innovation level of companies in terms of various dynamics. For example, Innovation Index that was developed by Indiana Business Research Center measures the innovation capacity of companies in USA based on human resources, efficiency and employment, economic dynamics, and economic welfare (Indiana Business Research Center, 2015).

On the other hand, indices developed at political level asses the innovation level of countries or regions based on some ratios such as efficiency in terms of budget allocated for R\&D or GDP. For example, State Technology and Science Index that was developed by Milken Institute tries to measure and compare the science and technology level of each state in USA based on some dynamics such as industrial, academic, and federal R\&D input, risk capital and entrepreneur infrastructure, human capital, technology and science labor, and technological growth(Devol, Klowden, \& Yeo, 2014). Similarly, indices such as Oslo Manual that was prepared by OECD and European Commission (OECD, 2014),Bogota Manual (Jaramillo, Lugones, \& Salazar, 2001) that was prepared for Latin America and Caribbean countries, and Innovation Capacity Index (Lopez-Claros \& Mata, 2011) that was prepared by many international researchers aim at measuring and comparing innovation levels of developed economies in America and Europe at political level. Additionally, Global Innovation Index (Cornell University, INSEAD, \& WIPO, 2015) measures and compares innovation levels of many countries based on some inputs such as environmental factors, human resources, infrastructure, market and business and outputs such as creativity, science, and technology.

Most of the indices above try to measure innovation on a country basis. Moreover, the indices were developed for developed countries and especially USA. In Turkey, some indices such as University Ranking by Academic Performance (URAP, Alasehir, 2010) which was developed to evaluate universities in terms of academic achievements and Entrepreneur and Innovative University Index which ranked universities based on their entrepreneurship and innovativeness performances were published. However, these indices approached innovation in terms of only academic publications, projects, education, courses, and intellectual properties and rank universities accordingly. This limitation encouraged us to design a model where the universities in Central Black Sea Region can monitor their innovation levels in terms of infrastructure, and especially high-tech and high-cost devices.

\section{Method}

The method of this study was literature review, and the data were obtained from the literature. In this study, various indices such as Global Innovation Index, Innovation Capacity Index, Innovation Efficacy Index, State Technology and Science Index, Portfolio Innovation Index, Academic Ranking of World Universities, and Bogota Manual were examined. Moreover, URAP (2015), which was developed by Middle East Technical University Institute of Informatics, and 
Entrepreneur and Innovator University Index, which was developed by TUBITAK (2015) and ranked universities based on their entrepreneurship and innovativeness were used to rank the universities based on their academic achievement.

URAP involves two dimensions which are education and research. This index evaluates universities based on their scores obtain from various criteria such as number of articles, number of articles per academic, number of citation, number of citation per academic, number of scientific document, number of scientific document per academic, number of doctoral students, rate of doctoral students, and number of doctoral students per academic.

On the other hand, Entrepreneur and Innovator University Index involves five dimensions which are scientific and technological competence, intellectual property pool, cooperation and interaction, entrepreneurship and innovativeness culture, and economic contribution and commercialization. This index evaluates universities based on their scores obtained from 23 indicators.

This study suggests the improvement of these indices by adding a new dimension, and presents a model that can be used by universities to monitor their innovation levels based on infrastructure and especially high-tech and high-cost devices.

\section{Research Model}

The model involves a total of six dimensions under innovation inputs and outputs containing measurable indicators. The dimensions under innovation inputs are human capital, social inclusion, and infrastructure while the dimensions under innovation outputs are R\&D activities, innovation connections, and innovation activities, all of which were developed based on literature. Naturally, some of these dimensions are similar to dimensions in other indices. Each dimension of the model illustrated in Figure 1 can be measured through various indicators objectively.

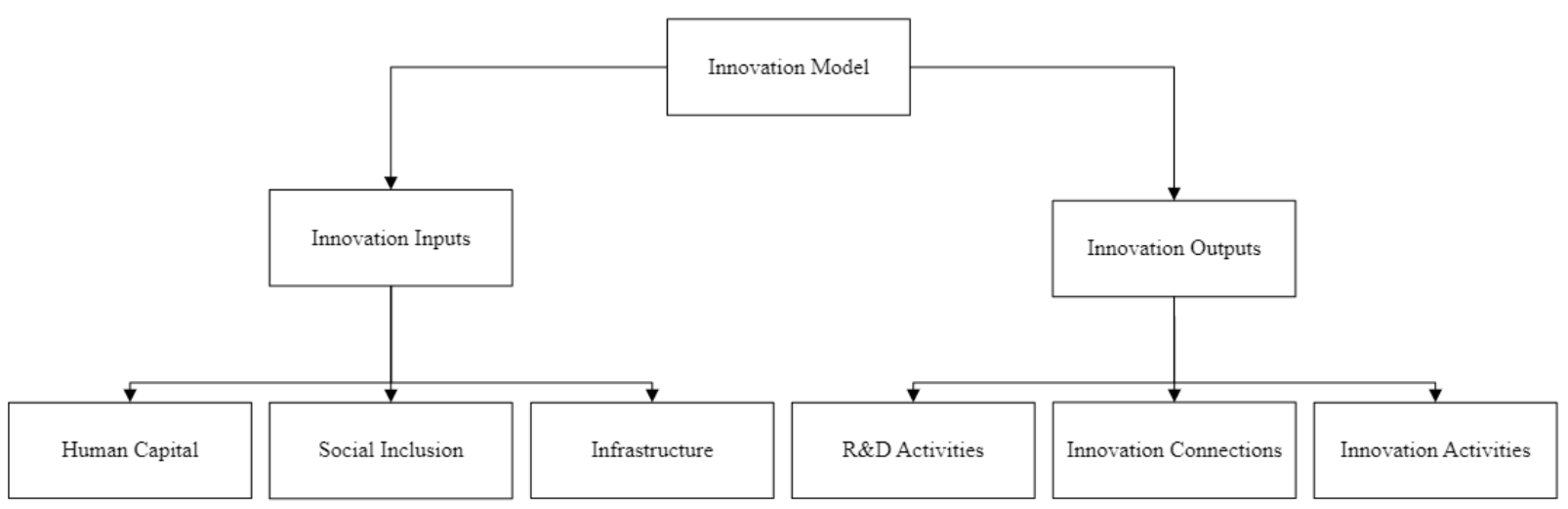

Figure 1. Research Model 


\section{Findings}

Dimensions determining the innovation level involve innovation inputs that are human capital, social inclusion, and infrastructure, and innovation outputs that are R\&D activities in the last five years, innovation connections, and innovation activities. The indicators that are used to measure these dimensions can be seen in Table 1.

Table 1. Indicators

\begin{tabular}{l} 
Innovation Inputs \\
Human Capital \\
\hline The number of students \\
The number of doctoral students \\
The number of master students \\
The rate of the number of doctoral students to the total number of \\
students \\
The rate of the number of master students to the total number of \\
students \\
The number of professors \\
The number of associate professors
\end{tabular}

The number of assistant professors

The number of lecturers

The number of research assistants

The number of students per academic

Qualified (academic) staff turnover

Innovation Outputs

R\&D Activities

The number of R\&D projects

The number of R\&D projects financed by SRP (Scientific Research Projects)

The number of R\&D projects financed by European Union

The number of R\&D projects financed by national funds (TEYDEB, TTGV, KOSGEB, SAN-TEZ)

Financial support for articles and congresses

\section{Innovation Connections}

The number of projects carried out by cooperation of university-industry

The number of projects carried out in cooperation with international institutions

\section{Innovation Activities}

The number of locally registered patents

The number of patents registered within the scope of Patent Cooperation Treaty (PCT)

The number of brand registry

The rate of engineering and science

Social inclusion

Certification programs

Public education

The number of R\&D companies in Techno-park

Infrastructure

Access to Information and Communication Technologies (ICT):

Software expenditures, ICT expenditures, the number of desktop computers, internet link speed

ICT use: the number of wired internet subscribers, the number of broadband subscribers, total number of internet users, broadband per

100 people

Online services

E-participation (Electronic document system use)

The number of articles indexed in SCI, SSCI, and SSCIE

The number of articles indexed in other indices

The number of articles indexed in refereed journals

The number of articles presented in international congresses

The number of articles presented in national congresses

The number of scientific and technical articles in non-refereed journals

citable documents $\mathrm{H}$ index

The number of ISO 9001 certificate of quality

The number of created ICT and organizational model

The number of international congresses organized by university

The number of external database subscriptions (such as ISI Web of The number of national congresses organized by university Science, IEEE Xplore, Scopus)

The number of science and technology labs

Installed power capacity (ICT infrastructure/lab)

R\&D density in investment expenditures

The number of high-tech devices, high-tech device capacity

A total of 56 indicators are suggested under six dimensions. However, some indicators such as the rate of engineering and science students, the number of $R \& D$ companies in Techno-park, R\&D density in investment expenditures, the number of R\&D projects, the number of locally registered patents, the number of brand registry, the number of science and technology labs, installed power capacity (ICT infrastructure/lab), the number of high-tech devices, and high-tech device capacity stand out since they enable more comprehensive evaluations.

\section{Conclusion}

Rapid dissemination of information and communication technologies in parallel with the development of information society has increased the transformation rate of world economy into an information-based economy where information is the basic economic input and research and development (R\&D) is the most important innovation source. Universities, where R\&D is among the most important activities, are the driving force of novel technologies, entrepreneur talents, national-international collaborations, and economic development. In today's technology-intensive competitive environment, universities need to be aware of their innovation levels and their rankings among other universities.

Various indices have been developed to measure the innovation at a corporate level and rank the institutions accordingly. 
The mostly known international indices are Global Innovation Index, Bogota Manual (Latin America and Caribbean countries), Innovation Capacity Index, Oslo Manual (North America and European Countries), State Technology and Science Index (America), Innovation Index (America), and Creative Class (America). These indices have been ranking institutions by taking into account the innovation inputs such as financial policies, education policies, and innovative environment and innovation outputs such as patents, technology transfer, and job performance. On the other hand, most of these indices focus on a specific country or region by measuring institutions at political or country level.

Moreover, some indices such as Entrepreneur and Innovative University Index which ranked universities based on their entrepreneurship and innovativeness performances and University Ranking by Academic Performance(URAP, Alasehir, 2010) which was developed to evaluate universities in terms of academic achievements approached innovation in terms of only academic publications, projects, education, courses, and intellectual properties. This limitation motivated us to design a sophisticated model where the universities can monitor their innovation levels in terms of infrastructure, which aims at increasing the collaboration among universities. The proposed model for universities in Central Black Sea Region can help them notice their deficiencies in their infrastructure especially high-tech and high-cost devices, and collaborate with other universities in the region to overcome their deficiencies.

Measurable indicators are proposed for dimensions of the model that were put forward after a careful examination of national and international indices, especially URAP and Entrepreneur and Innovative University Index. The dimensions based on the literature are composed of innovation inputs such as human capital, social inclusion, and infrastructure and innovation outputs such as R\&D activities, innovation connections, and innovation activities.

Central Black Sea Universities Platform was created through a protocol signed by eight universities (Tokat Gaziosmanpaşa University, Ondokuzmayıs University, Canik Başarı University, Amasya University, Ordu University, Giresun University, Sinop University, and Hitit University). This platform aims at taking common actions regarding development of universities, solutions of problems, and increasing the cooperation between universities and industry.

This study aims at helping universities monitor their own infrastructure deficiencies and overcome these by collaborating with other universities in their region, which is in parallel with the goals of Central Black Sea Universities Platform. Thus, the universities will collaborate with other universities that own high-cost devices rather than buying them, and overcome their deficiencies and develop their strategic plans accordingly.

This study proposes a solution for a current problem because most of the universities in Central Black Sea Region are developing universities and have infrastructure deficiencies. For example, universities with infrastructure deficiencies might need a high-cost device such as electron microscope during research. On the other hand, the universities that own this device might not be using it at full capacity. The model proposed in this study might help detect such devices and inform other universities about their use capacities.

The dimensions of the model based on literature can be presented to some expert to ensure content validity. Similarly, the weights of the dimensions can be reassessed based on expert opinions. The indicators in the final scale can be administered to universities in Central Black Sea Region, and these universities can be ranked. Thus, the data that will be obtained in future studies can be shared with the universities, and help them notice their aspects open to improvement and compare themselves with others.

The proposed model has the potential to be administered for all universities in future studies. Thus, universities can monitor their infrastructure deficiencies, and realize their spots at global and national level. Moreover, the proposed model can be added by other dimensions and indicators, and a new corporate model can be developed to determine innovation level of institutions in additions to universities.

\section{References}

Alasehir, O. (2010). University ranking by academic performance: A scientometrics study for ranking world universities (Doctoral Dissertation, Middle East Technical University).

Arpaci, I. (2010). E-government and technological innovation in Turkey: Case studies on governmental organizations. Transforming Government: People, Process and Policy, 4(1), 37-53. https://doi.org/10.1108/17506161011028795

Arpaci, I. (2011). Innovation policy and technological innovation in the public organizations. METU Studies in Development, 38(2), 111-123.

Arpaci, I. (2013). Organizational adoption of mobile communication Technologies (Doctoral dissertation). The Department of Information System. School of Informatics of Middle East Technical University.

Arpaci, I. (2015). Evaluation of the teaching effectiveness of the entrepreneurship course given in the faculty of education by the students. Sakarya University Educational Faculty Journal, 30, 138-154.

Arpaci, I., \& Gürbüz, T. (2011). Innovation in learning: Innovative tools and techniques for learning. International 
Journal of E-Adoption, 3(1), 29-37. https://doi.org/10.4018/jea.2011010104

Arpaci, I., \& Gürbüz, T. (2012). Innovation in learning: Innovative tools and techniques for learning (2nd Ed.). In Sharma, S. K. (Eds.). Adoption of Virtual Technologies for Business, Educational, and Governmental Advancements (pp. 117-125), Hershey, PA: IGI Global, Information Science Reference. https://doi.org/10.4018/978-1-4666-2053-7.ch009

Beatty, C. A., \& Gordon, J. (1991). Preaching the gospel: The evangelist of new technology. California Management Review, 33, 73-94. https://doi.org/10.2307/41166662

Cornell University, INSEAD, \& WIPO. (2015). Global Innovation Index. Retrieved September 26, 2015, from https://www.globalinnovationindex.org/content/page/gii-full-report-2015.

Devol, R. C., Klowden, K., \& Yeo, B. (2014). State Technology and Science Index, Milken Institute. Retrieved September 26, 2015, from http://statetechandscience.org/state-tech-and-science-report-2014.pdf

Evan, E. M. (1993). Organisation theory: Research and design.New York: Macmillan Publishing Company.

Goswami, S., \& Mathew, M. (2005). Definition of innovation revisited: An empirical study on Indian information technology industry. International Journal of Innovation Management, 9(3), 371-383. https://doi.org/10.1142/S1363919605001307

Hurt, H. T., Joseph, K., \& Cook, C. D. (1977). Scales for the measurement of innovativeness. Human Communication Research, 4(1), 58-65. https://doi.org/10.1111/j.1468-2958.1977.tb00597.x

Indiana Business Research Center. (2015). Innovation Index. Retrieved September 26, 2015, from http://www.statsamerica.org/innovation/reports/sections2/4.pdf.

Jaramillo, H., Lugones, G., \& Salazar, M. (2001). Bogota manual, Standardisation of indicators of technological Innovation in Latin American and Caribbean Countries. Retrieved September 26, 2015, from http://www.uis.unesco.org/Library/Documents/Bogota\%20Manual_eng.pdf.

Lawson-Body, A., Willoughby, L., Illia, A., \& Lee, S. (2014). Innovation characteristics influencing veterans' adoption of e-government services.The Journal of Computer Information Systems, 54(3), 34-44. https://doi.org/10.1080/08874417.2014.11645702

López-Claros, A., \& Mata, Y. N. (2011). Innovation Capacity Index, Policies and Institutions Underpinning Country Innovation: Results from the Innovation Capacity Index. Retrieved September 26, 2015, from http://www.innovationfordevelopmentreport.org/papers/101_LopezClaros_Mata.pdf.

Low, C., Chen, Y., \& Wu, M. (2011). Understanding the determinants of cloud computing adoption. Industrial Management \& Data Systems, 111(7), 1006-1023. https://doi.org/10.1108/02635571111161262

OECD. (2014). Oslo manual, the measurement of scientific and technological activities. Organisation for Economic Co-operation and Development. Retrieved September 26, 2015, from http://www.oecd.org/sti/inno/2367580.pdf.

Rogers, E. M. (1962). Diffusion of innovations. Glencoe: Free Press.

Rogers, E. M. (2003). Diffusion of Innovations (5th ed.). New York: Simon and Schuster.

Schumpeter, J. A. (1939). Business cycles: A theoretical, historical and statistical analysis of the capitalist process. New York: McGraw Hill.

Soosay, C. A., \& Hyland, P. W. (2005). Effect of firm contingencies on continuous innovation. International Journal of Innovation and Technology Management, 2(2), 153-169. https://doi.org/10.1142/S0219877005000447

TÜBіTAK. (2015). Girişimci ve Yenilikçi Üniversite Endeksi. Retrieved September 26, 2015, from http://www.tubitak.gov.tr/sites/default/files/gyue2015_siralama.pdf.

URAP. (2015). University Ranking by Academic Performance. Retrieved September 26, 2015, from http://tr.urapcenter.org.

Wang, Y. M., Wang, Y. S., \& Yang, Y. F. (2010). Understanding the determinants of RFID adoption in the manufacturing industry. Technological Forecasting and Social Change, 77(5), 803-815. https://doi.org/10.1016/j.techfore.2010.03.006

\section{Copyrights}

Copyright for this article is retained by the author(s), with first publication rights granted to the journal.

This is an open-access article distributed under the terms and conditions of the Creative Commons Attribution license which permits unrestricted use, distribution, and reproduction in any medium, provided the original work is properly cited. 